\begin{tabular}{|c|c|}
\hline 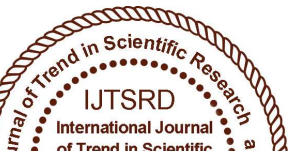 & $\begin{array}{l}\text { International Journal of Trend in Scientific } \\
\text { Research and Development (IJTSRD) }\end{array}$ \\
\hline $\begin{array}{lll} & \\
0\end{array}$ & International Open Access Journal \\
\hline and & ISSN No: $2456-6470$ | www.ijtsrd.com | Volume - 2 | Issue -3 \\
\hline
\end{tabular}

\title{
Assessing the Effects of Temperature and Relative Humidity on the Signal Strength of We FM Abuja, Nigeria During Harmattan Period
}

\author{
Ale Felix ${ }^{1}$, Abdullahi Ayegba ${ }^{2}$, John Yakubu ${ }^{3}$ \\ ${ }^{1,2}$ Department of Engineering and Space Systems, National Space Research and Development Agency, Abuja \\ ${ }^{1}$ Department of Electrical/Electronic Engineering, University of Abuja, Nigeria \\ ${ }^{2}$ Mathson Research Centre- A Division of Mathson Group of schools, Nigeria \\ ${ }^{3}$ Department of Electrical/Electronic Engineering, Federal Polytechnic, Idah, Kogi State, Nigeria
}

\section{ABSTRACT}

The effect of temperature and relative humidity on WE FM radio station (106.3MHz) Abuja, Nigeria, during Harmattan period was carried out with the measurement of frequency modulation (FM) signal strength by digital CATV signal meter and the temperature and relative humidity measured by digital Hygrometer/thermometer.

It was observed that the signal strength was lower during the sunny period but higher in the morning and evening when there was little or no sun. It was also found out that both temperature and relative humidity have effect on the radio station signal strength with the correlation coefficient of -0.79 between signal strength and temperature, and 0.91 between signal strength and relative humidity.

It was concluded from the correlation coefficient that signal strength is directly proportional to the relative humidity but inversely proportional to the temperature, but the effect of both was higher in harmattan than in rainy season when compared to our the result of our previous work on the same radio station.

Keywords: radio frequency, relative humidity, signal strength, Temperature.

\subsection{INTRODUCTION}

Harmattan period is a period of the dry season that is characterized with dust and in some cases haze or "unclear" atmosphere. This will undoubtedly affect the how some atmospheric components such as temperature, pressure, relative humidity, etc affect the propagation of radio signal transmitted.

In communications, radio wave propagation is concerned mainly with the properties and effects of the medium situated between the transmitting and receiving antennas (Amajama, 2016).

Frequency modulation is the transmission of communication signal by varying the frequency of the signal or carrier wave while the amplitude remains constant.

Temperature is the degree or extent of coldness or hotness of a body, object or particles, and it measures the average kinetic energy of particles. That is, the average kinetic energy of a radio signal transmitted from a radio station as in the case of this study is affected by the temperature of the environment through which it is being propagated. This can result in the area of coverage of the radio signal transmitted.

Relative humidity is defined as the amount of moisture in the air or atmosphere. When the quantity of moisture in the air at a particular location changes, its effect on radio signal changes. Also, when relative humidity of an area changes due to change in season, so also it effects on transmitted radio signal varies.

When the wave passes through the water particles, a part of its energy is absorbed and a part is scattered (cdn.intechopen.com/pdfs- wm/16080.pdf.) 
According to Amajama (2015), the condition of the atmosphere has significant effect on signal and can result to loss signal. He observed that the major atmospheric elements that the components of the weather are the atmospheric temperature, pressure, humidity and wind speed and direction, and that finding how each or some of these components affect the radio signal strength is very paramount and thus, this work is considering temperature and relative humidity in the first instance.

Michael, (2013) stated that some the factors that affect radio wave propagation such as rain, wind, temperature, and water content of the atmosphere can combine in different ways to affect radio wave propagation to a point that some combination may cause radio signals to be heard far away beyond its ordinary range or resulting in attenuation that can make the signal not to be heard even over a normally satisfactory path.

Some related works have been carried out but very little in Nigeria. Roshidah et al., (2016) conducted a similar research in Malaysia using weather station (Vantage Pro 2, USA) and Spectrum analyser for frequencies $945 \mathrm{MHz}, 383 \mathrm{MHz}, 1800 \mathrm{MHz}$ and 2160 MHz. Spectrum analyser was used to measure the radio signal while the weather station was used to measure the temperature. They found out that there was a relationship between radio signals and the change of temperature, and that the correlation coefficient between radio signal and temperature for $945 \mathrm{MHz}$, was -0.085 , for $383 \mathrm{MHz}$ was 0.249 , for $1800 \mathrm{MHz}$ was 0.268 and for $2160 \mathrm{MHz}$ was 0.134 .

Amajama (2016) worked on radio signal strengths of Cross River State Broadcasting Co-operation Television (CRBC-TV on the frequency of 519.25 $\mathrm{MHz}$ (UHF) using Cable TV analyzer and weather instruments. Cable TV analyzer was used to measure the radio frequency signal strength while the weather instrument were used to measure temperature, atmospheric pressure, relative humidity and wind speed and direction. He observed from his results that if other measured metrological components including wind speed and direction were observed constant, radio signal strength is inversely proportional to atmospheric temperature, with the correlation coefficient of -0.93 .

Ale, et al., (2017) worked on the same radio station, WE FM , $106.3 \mathrm{mHz}$ Abuja. They found out that radio frequency signal strength is affected by temperature and relative humidity. It was concluded from the correlation coefficients on both days that radio frequency signal strength is inversely proportional to the atmospheric temperature and directly proportional to relative humidity. It can also be concluded that the effect of relative humidity and temperature was higher on cloudy days than on clear sky days.

Although, the same work was done on the radio station by us, it was during the rainy season, and the result of rainy season may not be the same with that in dry season. That is, the effect of temperature and relative humidity of radio signal strength during rainy season may be different from the effects during dry season in general and harmattan in particular. This work will study how FM radio (WE FM radio station) signal strength is affected by temperature and relative humidity during harmattan period.

\subsection{The Measurement Location}

The experimental setup was done in a residence in Karshi, a satellite community in Abuja Municipal Area council, Federal Capital Territory, Abuja. The location of the measurement or experiment is along the boundary of federal capital territory and Nasarawa state, and is on latitude $8.83^{\circ} \mathrm{N}$ and longitude $7.56{ }^{0} \mathrm{E}$. It has some hills and a very few trees with short grasses. WE FM radio station is located in Maitama, Abuja Municipal Area council. The station is located on latitude $9.10^{0} \mathrm{~N}$ and longitude $7.44^{\circ} \mathrm{E}$. It is in the heart of Abuja city. The radio station transmits on the frequency, 106.3 MHz.

\subsection{Materials and method}

\subsection{Materials}

The work made use of Community Access Television (CATV) signal meter, digital Hygrometer/thermometer, Microsoft excel software package. The CATV signal level meter is S110 model and operates on a 9v DC inbuilt battery.

The digital Hygrometer/thermometer has temperature measurement range of $-10^{\circ} \mathrm{c}$ to $+50^{\circ} \mathrm{c}$, and relative humidity measurement range of $+10 \%$ to $+99 \%$. It has the accuracy of $+/-1^{0} \mathrm{c}(1.8 \mathrm{~F})$ and $+/-5 \%$. It operates on a $1.5 \mathrm{v}$ DC battery. 


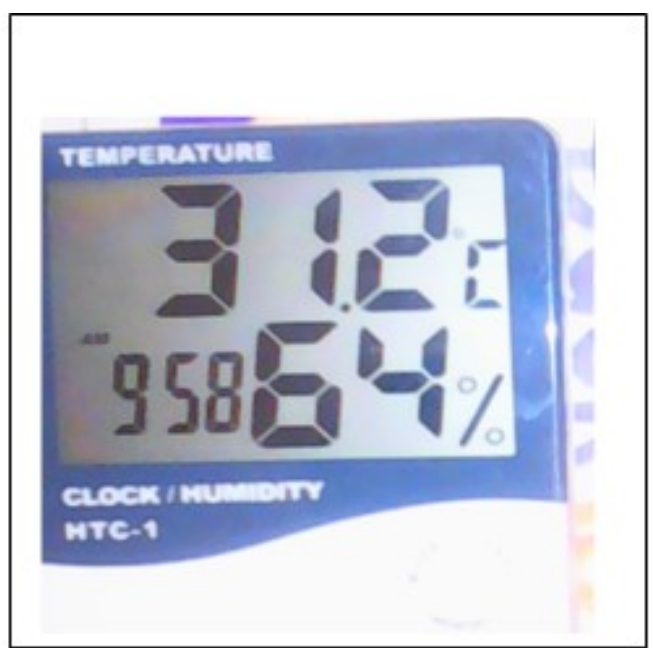

Plate 2.0: Digital thermometer/hygrom eter



Plate 1: Digital CATV signal strength meter

\subsection{Methods}

It involved the connection of coaxial cable to a Yagi Uda antenna and mounted on a vertical pole at about $12 \mathrm{~m}$ tall. The other end of the cable was attached to a connector which was then connected to the CATV meter through its connector. The device was then put on by pressing the on/off button. The desired frequency $(106.3 \mathrm{MHz})$ was inputted into the device, and when "OK" was pressed, it will start to display the signal strength though varying from time to time.

The digital Hygrometer/thermometer puts itself on automatically as soon as the battery was inserted in its position. The direction of the antenna in the direction of higher signal as displayed on the meter screen, and it was left at the fixed position and direction throughout the study period.
At each point of the readings, the highest and stable value of the signal strength was taken on the CATV signal meter and the temperature and relative humidity were also read from the Hygrometer/thermometer simultaneously with the signal strength. The processes were carried out from 5.00 am to $8.00 \mathrm{pm}$ at one hour interval on 10th and 11 th of January, 2018.

The data was represented graphically and in tabular forms, while correlation analysis was used to assess the relationship between the signal strength and temperature, and between the signal strength and relative humidity.

\subsection{Results and Discussions}

The Measured signal strength, temperature and relative humidity are shown in table 1.0. The experiment was conducted on the 10th and 11th of January, 2018 when there was intense effect of Harmattan, and the average of the two days reading was taken to have a single column value for each of the quantities as represented in table 1.0. The results on the table shows that irregular variations of radio frequency signal strength was experienced during this period in the study area. The variation of temperature is such a way that it increased steadily from 5.00am (except by $1.00 \mathrm{pm}$ where a reduction in temperature occurred) till $4.00 \mathrm{pm}$ when it started decreasing. Like in the case of signal strength, there was fluctuation in the variation of relative humidity over the period.

Table 1.0: Measured signal strength, temperature and relative humidity

\begin{tabular}{|l|l|l|l|l|}
\hline S/N & Time & $\begin{array}{l}\text { signal } \\
\text { strength } \\
(\mathbf{d B u V})\end{array}$ & $\begin{array}{l}\text { Temp } \\
\left({ }^{0} \mathrm{c}\right)\end{array}$ & $\begin{array}{l}\text { RH } \\
(\%)\end{array}$ \\
\hline $\mathbf{1}$ & $5.00 \mathrm{am}$ & 45.2 & 26.8 & 27 \\
\hline $\mathbf{2}$ & $6.00 \mathrm{am}$ & 46.3 & 26.4 & 25 \\
\hline $\mathbf{3}$ & $7.00 \mathrm{am}$ & 47.0 & 26.3 & 27 \\
\hline $\mathbf{4}$ & $8.00 \mathrm{am}$ & 44.9 & 25.2 & 26 \\
\hline $\mathbf{5}$ & $9.00 \mathrm{am}$ & 44.9 & 26.1 & 26 \\
\hline $\mathbf{6}$ & $10.00 \mathrm{am}$ & 44.6 & 27.6 & 25 \\
\hline $\mathbf{7}$ & $11.00 \mathrm{am}$ & 44.7 & 27.8 & 24 \\
\hline $\mathbf{8}$ & $12.00 \mathrm{pm}$ & 43.4 & 29.9 & 22 \\
\hline $\mathbf{9}$ & $1.00 \mathrm{pm}$ & 40.0 & 29.1 & 20 \\
\hline $\mathbf{1 0}$ & $2.00 \mathrm{pm}$ & 42.3 & 30.6 & 19 \\
\hline $\mathbf{1 1}$ & $3.00 \mathrm{pm}$ & 39.4 & 30.3 & 19 \\
\hline
\end{tabular}


International Journal of Trend in Scientific Research and Development (IJTSRD) ISSN: 2456-6470

\begin{tabular}{|l|l|l|l|l|}
\hline $\mathbf{1 2}$ & $4.00 \mathrm{pm}$ & 40.2 & 31.7 & 18 \\
\hline $\mathbf{1 3}$ & $5.00 \mathrm{pm}$ & 41.5 & 30.3 & 19 \\
\hline $\mathbf{1 4}$ & $6.00 \mathrm{pm}$ & 43.0 & 29.8 & 23 \\
\hline $\mathbf{1 5}$ & $7.00 \mathrm{pm}$ & 43.1 & 29.7 & 24 \\
\hline $\mathbf{1 6}$ & $8.00 \mathrm{pm}$ & 44.2 & 29.7 & 25 \\
\hline
\end{tabular}

Also from the result, the average radio frequency signal strength over the period is $43.4 \mathrm{dBuV}$, while the while the minimum and maximum radio frequency signals are $39.4 \mathrm{dBuV}$ and $47 \mathrm{dBuV}$ respectively. The average temperature and relative humidity are also $28.58^{\circ} \mathrm{c}$ and $23.06 \%$, while the minimum and maximum temperature and relative humidity are $25.2^{\circ} \mathrm{c}$ and $31.7^{\circ} \mathrm{c}$, and $18 \%$ and $27 \%$ respectively. As shown in figure 3.0, the signal strength of the radio station received in the study area (Karshi, Abuja) was higher in the morning and evening with lower signal strength during the sunny period. The signal strength was high between 5.00am and 7.00am when it started decreasing as the sun rises with fluctuation of signal between $1.00 \mathrm{pm}$ and $3.00 \mathrm{pm}$ when it started rising gently again until $8.00 \mathrm{pm}$.

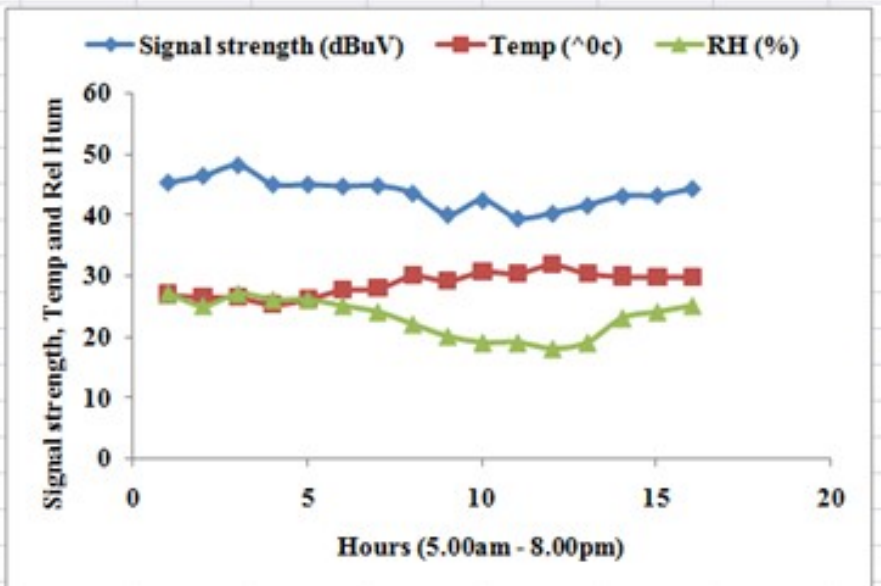

Fig. 3.0: Graphical of signal strength, temperature and relative humidity

The graphical relationship of the temperature, relative humidity and radio frequency signal strength in figure 3.0 shows that the variation of the received signal strength is influenced by the change in temperature and relative humidity. The relative humidity is observed to be low during the sunny period while the temperature is high during the sunny period of the day. As stated earlier, the received signal strength is also low during the sunny period of the day, thus

making it to be related directly with relative humidity and inversely with the temperature.

In addition, the correlation coefficient analysis carried out revealed that the coefficient of correlation between the received signal strength and the temperature are -0.79 temp, while the correlation coefficient between the signal strength and the relative humidity is 0.91 . This means that the relationship between the signal strength with temperature is $79 \%$, and with the relative humidity is $91 \%$. This implies that both temperature and relative humidity have effects on radio frequency signal strength during harmattan. However, signal strength increases with decrease in temperature due to the negative correlation coefficient $(-0.79)$ while the signal strength increases with increase in relative humidity because of positive correlation coefficient (0.91).

This result is in line with the result of the work done on the same radio station (WE FM, 106.3MHz) carried out during rainy season (September, 2018) by Alex et $a l$, in which we concluded that the signal strength directly varies with relatively humidity and inversely varies with the ambient temperature. However, the effect of both temperature and relative humidity during our study was less than the effect during the Harmattan because from our findings then, correlation coefficients of the temperature and signal strength for the two days were -0.42369 and -0.51878 while relative humidity and signal strength correlation coefficients were 0.29 and 0.39 . Thus, the effect during the harmmatan is far more than the effect during the rainy season.

\subsection{CONCLUSION}

The effect of temperature and relative humidity on WE FM (106.3 MHz) radio station Abuja, Nigeria has been studied during the Harmattan period. The measurement of frequency modulation (FM) signal strength was done by digital CATV signal meter, while the temperature and relative humidity were measured by digital Hygrometer/thermometer.

From the result, it was observed that the signal strength was lower during the sunny period but higher in the morning and evening when there was no or little sunshine. It was observed also that relative humidity was lower during sunny period of the day while the temperature was higher during sunny period. It was found out that both temperature and relative humidity have effect on the radio station 
signal strength with the correlation coefficient of 0.79 between signal strength and temperature, and 0.91 between signal strength and relative humidity.

It can be concluded from the correlation that signal strength is directly proportional to the relative humidity but inversely proportional to the temperature, but the effect of both is very high in harmattan compared to rainy season taking into cognizance the result of the previous work on the same radio station. This information will assist radio engineers, satellite communication engineers and link designers.

\subsection{RECOMMENDATION}

The study assessed the effect of temperature and relative humidity on the signal strength of radio station, WE FM 106.3MHz, Abuja both in rainy season and in dry season (Harmattan period), it is recommended that the effect of atmospheric pressure on the radio station signal strength be carried out on the same station.
International Journal of Engineering Research and General Science. Vol. 4, No. 2, pp. 619-622

6. Michael O. A. (2013). "Investigation of the Effect of Ground and Air Temperature on Very High Frequency Radio Signals". Journal of Information Engineering and Applications. Vol.3, No.9, pp. 16-22

7. Prasad, M. V. S. N., Rama R. T., Iqbal A., and Paul, K. M, (2006). "Investigation of VHF signals in bands I and II in southern India and model comparisons', Indian Journal of Radio and Space Physics, Vol. 35, pp.198 - 205.

8. Roshidah M, Marhamah M. S., Sabri A., Roslan U., Yew B. S., Nor H. S. ( 2016). "Temperature Effect on The Tropospheric Radio Signal Strength for UHF Band at Terengganu, Malaysia". International Journal on advanced science engineering information technology. Vol. 6. No. 5 , pp. 774

9. Atmospheric attenuation due to humidity (2011), Electromagnetic waves. Retrieved February, 2018, from cdn.intechopen.com/pdfs- wm/16080.pdf.

\section{REFERENCES}

1. Ale Felix, Agboola A. Olufemi, Halidu D. Ibrahim, Abdullahi Ayegba, Jegede John Olu, Wysenyuy Desmond Fonyuy, Ademu Victor (2017): "Investigation of The Influence Of Atmospheric Temperature And Relative Humidity On Fm Radio Signal Strength: A Case Study Of We Fm Abuja". International Journal Of Scientific \& Technology Research Volume 6, Issue 11, pp $70-74$

2. Amajama, J. (2015). "Association between Atmospheric radio wave refractivity and UHF Radio signal". American International Journal of Research in Formal, Applied and Natural Sciences, Vol. 13, No. 1, pp. $61-65$.

3. A. O. Michael (2013). "Further Investigation into VHF Radio Wave Propagation Loss over Long Forest Channel". International Journal of Advanced Research in Electrical, Electronics and Instrumentation Engineering. Vol. 2 No. 1, pp. $705-710$.

4. Blaunstein, N., D. Censor, D. Katz, A. Freedman, and I. Matityahu (2003). "Radio propagation in rural residential areas with vegetation," Progress In Electromagnetics Research, Vol. 40, pp. 131153.

5. J. Amajama (2016). "Impact of Atmospheric Temperature on (UHF) Radio Signal". 